\title{
Mechanical and thermal properties of starch films reinforced with microcellulose fibres
}

\author{
${ }^{1}$ Nordin, N., ${ }^{1,2, *}$ Othman, S.H., ${ }^{1}$ Kadir Basha, R. and ${ }^{1,2}$ Abdul Rashid, S. \\ ${ }^{1}$ Department of Process and Food Engineering, Faculty of Engineering, Universiti Putra Malaysia, 43400, \\ UPM Serdang, Selangor, Malaysia \\ ${ }^{2}$ Institute of Advanced Technology, Universiti Putra Malaysia, 43400, UPM Serdang, Selangor, Malaysia
}

\begin{abstract}
Article history:
Received: 28 May 2018

Received in revised form: 12

September 2018

Accepted: 12 September 2018

Available Online: 6

November 2018
\end{abstract}

Keywords:

Food packaging,

$\mathrm{NaOH} /$ urea,

Mechanical,

Microcellulose fibres,

TGA

DOI:

https://doi.org/10.26656/fr.2017.2(6).110

\begin{abstract}
The use of starch as food packaging material has drawn increased attention due to its biodegradability, availability, and cost-effective. In order to improve the limitations of starch films in terms of mechanical and thermal resistance, the bio-composite concept was employed. In this work, microcellulose fibres (MCF) were incorporated into thermoplastic starch (TPS) films at various loading contents (1, 5, and $10 \mathrm{wt} \%)$. The MCF was prepared via $\mathrm{NaOH} /$ urea dissolution, followed by ultrasonication. The obtained MCF was characterized by FTIR and FESEM, and the size was in the range of 2 to $15 \mu \mathrm{m}$ in diameter and $150 \mu \mathrm{m}$ to hundreds of micrometres in length. The effect of the MCF addition on mechanical and thermal properties of starch films was investigated using universal testing machine and thermogravimetric analysis (TGA), respectively. Due to similar polysaccharide structures and good interfacial interactions, the tensile strength (TS) and the elongation at break (EAB) of the films increased with the addition of MCF, but only at $1 \mathrm{wt} \%$ loading content. Meanwhile, there was no significant improvement in the degradation temperature of the composite films, due to the presence of hemicellulose compounds that interrupted the crystallinity of the MCF. The results indicated that the MCF has the potential to be utilized as reinforcement in bio-based polymers for food packaging applications.
\end{abstract}

\section{Introduction}

According to European Bioplastics (2017), 8.3 billion tonnes of plastics have been produced worldwide, since the early production in the 1950s. The trend seems to increase steadily from 2015 (322 million tonnes) to 2016 (335 million tonnes) whereby in Europe, the largest application $(40 \%)$ of the plastics is in the packaging sector. Packaging plays an integral part in food industry whereby it crosses different stages of the food chains, especially to package the end products. Due to that, different types of plastics such as polyethylene (PE), polypropylene (PP), and polyamide (PA), have been tailor-made to meet various purposes. The concern is that, from the total production of plastics, only $9 \%$ was recycled, $12 \%$ was incinerated and about $79 \%$ of the plastics are accumulated in the landfills (Geyer et al., 2017). These kinds of plastics are continuously manufactured due to their great combination of flexibility, strength, and stability for packaging purposes. However, the growing concerns over the sustainability of the environment, depletion of the petroleum resources and demands on bio-economy and green products has led to significant development of bio-based polymers.

Among the potential bio-based polymers, starch has been considered as a promising material for food packaging owing to its renewability, availability, costeffective, and ecological functions (Othman, 2014). Numerous studies have testified the potential of starch to form films that are odourless, tasteless, colourless, transparent, non-toxic, and biodegradable (Mali et al., 2005; Ma et al., 2008; Avérous and Halley, 2009; Pelissari et al., 2009; Wittaya, 2012; Sadegh-Hassani and Nafchi, 2014; Alcàzar-Alay and Meireles, 2015; Chen et al., 2017; Mohamed et al., 2017). In order to produce films with enhanced workability and properties, plasticizers such as glycerol and sorbitol are added into native starch under heat and shear to form thermoplastic starch (TPS) (Sanyang et al., 2015). Due to granules disruption and plasticization, TPS has similar behavior as the common thermoplastic polymers. However, TPS has two main disadvantages; poor mechanical properties and low thermal stability.

The emerging technologies and the growing 
consumer demands have stimulated the innovation in food packaging industries. Bio-based composites reinforced by cellulose fibres have been considered as a promising concept as these bio-composites possessed several desired properties such as high surface area, excellent performance, unique morphology, low density, biodegradability and renewability (Siquera et al., 2010; Trache et al., 2016). The potential of cellulose fibres as reinforcement have been known since decades and attracted increased interest in research and product development.

Previous studies have reported the inclusion of microcrystalline cellulose (MCC) and microfibrillated cellulose (MFC) into various polymers. For instances, MCC which generally being obtained by acid hydrolysis has been incorporated into starch (Maulida et al., 2016; Coelho et al., 2017), soy-protein (Li et al., 2015; Liu et al., 2017), agar (Shankar and Rhim, 2016), chitosan (Li et al., 2012), poly (lactic) acid (Haafiz, et al., 2013), poly(3hydroxybutyrate) (El-Hadi, 2013), and polyvinyl alcohol (PVA) (Ali et al., 2014). It has been known for the superior stiffness which could enhance the overall performance of the polymers. Meanwhile, microfibrillated cellulose (MFC) has also gained much interest as reinforcement in composite materials. Some of the recent works include the incorporation of MFC into starch (Lendvai et al., 2016; Soykeabkaew et al., 2017), PLA (Suryanegara et al., 2017), poly (propylene carbonate) (Qi et al., 2016), and PVA (Ali et al., 2014). Besides its abundance and renewability, it has an outstanding modulus, high surface area, and biocompatibility. By comparing the effectiveness of MCC and MFC as reinforcement, both have been known for the remarkable reinforcing capacity. However, MFC has a higher aspect ratio due to its long and entangled fibrils rather than the rod-like cellulose crystals of MCC. This proposed that MFC is more suitable as a matrix material and reinforcement components in various products (Jonoobi et al., 2015; Abdul-Khalil et al., 2017).

At present, MFC is mainly produced via two routes, mechanical processes, and controlled acid hydrolysis. Some of the mechanical treatments used are grinding, electrospinning, high-intensity ultrasonication, or wet disk mill (Jonoobi et al., 2015) but these methods undoubtedly require extremely high energy cost. Meanwhile, a planned acid hydrolysis can also yield MFC but this process will involve the use of strong acids such as hydrochloric acid or sulphuric acid to hydrolyze the cellulose pulps (Mandal and Chakrabarty, 2011; Shankar et al., 2015; Azrina et al., 2017). These harmful chemicals must be washed repeatedly by centrifugation and this has cause troublesome and a lot of chemical waste. Alternatively, some researchers have used the chemo-mechanical method (Jonoobi et al., 2011) which used chemicals like sodium hypochlorite, acetic acid, and TEMPO-mediated oxidation prior to mechanical treatment.

Considering the use of strong acid and harmful chemicals, there is a need for a more facile and safer method. Therefore, this work presents the properties of microcellulose fibres (MCF) produced via the chemomechanical method using $\mathrm{NaOH}$ and urea, combined with ultrasonication prior to the incorporation into starch films. The properties of the produced MCF were characterized by field emission scanning electron microscopy (FESEM) analysis and Fourier transform infrared (FTIR) spectroscopy. The effects of MCF concentration on mechanical and thermal properties of the starch film were also explored.

\section{Materials and methods}

\subsection{Preparation of microcellulose fibres (MCF)}

Dried cellulose pulps were obtained by WARIS NOVE Sdn. Bhd, Malaysia. An amount of $3 \mathrm{~g}$ of dried cellulose pulps was added into $100 \mathrm{~mL}$ of $7 \% \mathrm{w} / \mathrm{w}$ $\mathrm{NaOH}$ (R\&M, United Kingdom) and 12\% w/w urea (R\&M, United Kingdom), and stirred at room temperature using magnetic stirrer (Favorit, PLT Scientific, Malaysia) at $1,000 \mathrm{rpm}$, for 30 mins. Then, the sample was kept in the freezer $\left(-18^{\circ} \mathrm{C}\right)$ for $16 \mathrm{hrs}$ to facilitate the bonding and reactions of $\mathrm{NaOH}$ onto cellulose chains. Next, the content was stirred for 15 mins until dissolved then added with $1000 \mathrm{~mL}$ of deionized water. The mixture was then centrifuged (Hettich EBA 200, Germany) at $1008 \mathrm{x} g$ for 10 minutes. Finally, the content was washed with deionized water for 6 to 7 times to remove the residue of urea and $\mathrm{NaOH}$, and then underwent ultrasonication (Q500 Sonica, New York) for 5 mins at $75 \%$ amplitude. The content was kept at $4{ }^{\circ} \mathrm{C}$ until further use.

\subsection{Field emission scanning electron microscopy (FESEM)}

The FESEM micrographs were viewed using NOVA NanoSEM 230 (FEI, United States) with an accelerating voltage of $3 \mathrm{kV}$ in order to examine the morphology and surface structure of the MCF after treatment. MCF samples were dried at $50^{\circ} \mathrm{C}$ for 3 days and coated with gold before viewed using FESEM to avoid overcharging and any disturbance to the molecular structure.

\subsection{Fourier transform infrared (FTIR) spectroscopy}

The possible changes in the functional groups of the obtained MCF were determined using FTIR (Nicolet 
6700 Thermo Nicolet, Thermo Scientific, United States). FTIR spectra were recorded using an infrared spectrometer in the range of 400 to $4,000 \mathrm{~cm}^{-1}$.

\subsection{Preparation of MCF/TPS composite films}

MCF/TPS composite films were prepared using the solvent casting method. An amount of $3 \mathrm{~g}$ cornstarch (Cap Bintang, Malaysia) was dissolved in $100 \mathrm{~mL}$ of distilled water, containing glycerol (fixed at $30 \mathrm{wt} \%$ of TPS) and the solution was heated for 30 mins with stirring until the mixture was gelatinized. Then, the various amount of MCF (1, 5 and $10 \mathrm{wt} \%$ of TPS) was dispersed into the mixture and stirred for another 15 mins. Then, the film forming solution underwent ultrasonication for 5 mins at $50 \%$ amplitude prior to casting into $140 \mathrm{~mm}$ petri dish. The same procedure was applied for the preparation of the neat starch film. The films were dried under air-conditioned at $21{ }^{\circ} \mathrm{C}$ for 48 hrs. The dried films were peeled off from the casting plate and conditioned in desiccator set at $25^{\circ} \mathrm{C}$ and $55 \%$ relative humidity for $48 \mathrm{hrs}$ before further characterization.

\subsection{Thickness and mechanical properties of MCF/TPS composite films}

The film thickness was measured using a hand-held micrometer with an accuracy of $0.01 \mathrm{~mm}$ at five random points and the average value was determined.

Mechanical test was performed using Universal Testing Machine (Model 5566, Instron Engineering Corporation, United States). Films samples were cut into rectangular strips $(100 \mathrm{~mm} \times 15 \mathrm{~mm})$ and the tensile strength (TS) and the elongation at break (EAB) were measured in accordance to standard method ASTM D882-02 (ASTM, 2002).

\subsection{Thermogravimetric analysis (TGA)}

The thermal degradation behaviour was analysed by TGA Instrument, Mettler Toledo (Model TGA/DSC 1 HT, Switzerland). An amount of $10 \mathrm{~g}$ sample was put into aluminium pans under nitrogen flow at a rate of $25 \mathrm{~mL} /$ min, in a temperature range from $25^{\circ} \mathrm{C}$ to $500^{\circ} \mathrm{C}$ with a heating rate of $10^{\circ} \mathrm{C} / \mathrm{min}$.

\section{Results and discussion}

\subsection{Characterization of microcellulose fibres}

Despite dissolution is a big issue for cellulose, urea and $\mathrm{NaOH}$ were apparent to dissolve the dried cellulose pulps. The dissolution of the dried cellulose pulps in $\mathrm{NaOH}$ and urea was observed to result in a change of colour of the cellulose fibres from brown to white colour after the treatment. It is deduced that the mixture of
$\mathrm{NaOH}$ and urea can act as a bleaching treatment for the cellulose fibres besides dissolving the cellulose fibres prior to the rupturing process via ultrasonication treatment. Zhang et al. (2013) were also in agreement, supporting that the $\mathrm{NaOH}$ acted as a swelling solvent, which penetrated the amorphous regions in the cellulose chains, leading to fibre swelling. Meanwhile, urea has been said not to have direct interactions with cellulose chains, but it helps to stabilize the $\mathrm{NaOH} /$ cellulose mixture (Zhou et al., 2004, Luo and Wang, 2017; Wang et al., 2017). In particular, the interactions between the amino group of urea with the $\mathrm{OH}^{-}$ions of $\mathrm{NaOH}$ was believed to enhance the interactions between the $\mathrm{Na}^{+}$ ions with the cellulose chains (Jiang et al., 2014). Furthermore, this reaction was done at low temperature $\left(-18^{\circ} \mathrm{C}\right)$ to facilitate the bonding between the $\mathrm{Na}^{+}$ion of the $\mathrm{NaOH}$ with the cellulose chains. It is deduced that the treatment of the cellulose fibres in $\mathrm{NaOH}$ and urea was able to destroy the hydrogen bonding between the cellulose molecules and subsequently open the structural chains to form a special loose structure. The loose and fully swelled structure of the cellulose fibres allows the breakup process via ultrasonication to produce smaller size of cellulose, which we called as microcellulose fibres (MCF).

To further observed the morphological structure of the obtained MCF, FESEM micrographs were taken at different magnifications to visualize the structure, homogeneity, and dimensions; presented in Figure 1a to Figure 1c.

Figures 1a - 1c show that the structure of the obtained MCF was long individual fibrils, relatively flat and entangled to each other forming a rope-like structure. At higher magnification, it can be seen that the surface of the fibres was distorted and wrinkled, in agreement with the results obtained by Luo and Wang (2017). The MCF was irregular in diameter and length, whereby the diameter was in the range of 2 to $15 \mu \mathrm{m}$, and the length was varied from $150 \mu \mathrm{m}$ to several hundred micrometers. This has led to the relatively high aspect ratio of length to diameter and the non-uniformity of the size distribution.
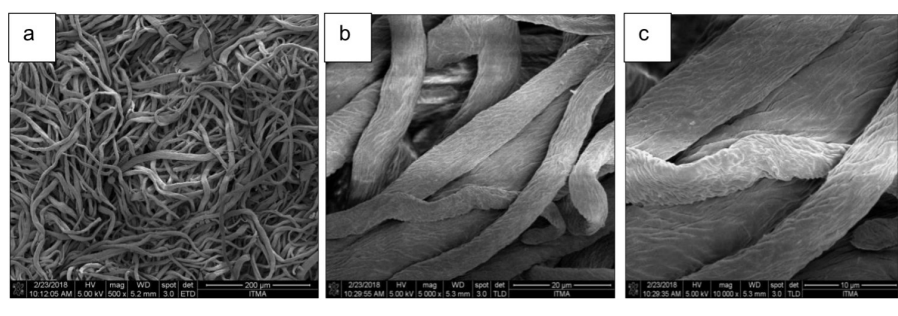

Figure 1. FESEM micrographs of microcellulose fibres at magnifications: (a) $\times 500$, (b) $\times 5,000$, and (c) $\times 10,000$ 


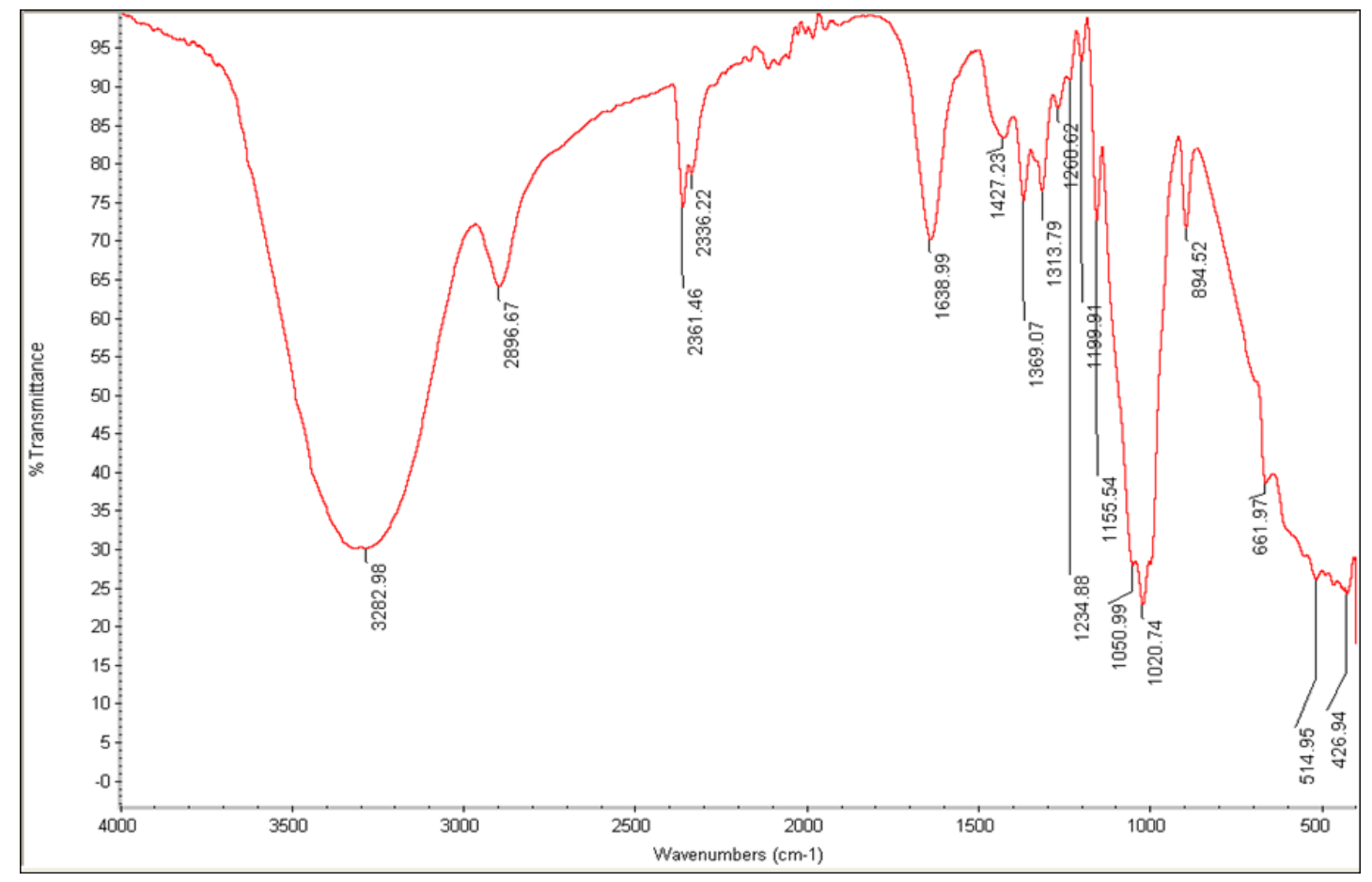

Figure 2. FTIR spectra of MCF

\subsection{Characterization of MCF/TPS composite films}

\subsubsection{FTIR analysis}

The changes in the chemical structure of the treated cellulose fibres were analysed using FTIR. The FTIR spectra in Figure 2 depicts two regions of absorbance; the first one at low wavenumbers $\left(500-1700 \mathrm{~cm}^{-1}\right)$ and the second one at higher wavelengths $\left(2300-3500 \mathrm{~cm}^{-1}\right)$. This observation was in line with the studies done by Moràn et al. (2008) and Lani et al. (2014). The broadband located in the range of 3600 to $3000 \mathrm{~cm}^{-1}$ region was attributed to the hydroxyl group $\mathrm{O}-\mathrm{H}$ stretching vibrations, and the peak at $2896.67 \mathrm{~cm}^{-1}$ corresponded to aliphatic saturated $-\mathrm{CH}$ stretching vibrations. The peaks appearing at wavenumber 2330 to $2400 \mathrm{~cm}^{-1}$ was ascribed to triple bonds, $\mathrm{C} \equiv \mathrm{N}$ due to the interaction of urea and cellulose fibres. The peak presents at $1638 \mathrm{~cm}^{-1}$ was related to the $\mathrm{O}-\mathrm{H}$ bending of adsorbed water by the cellulose. The peak at $1427 \mathrm{~cm}^{-1}$ was attributed to the $-\mathrm{CH}_{2}$ deformation vibration that is a type of the "crystallinity band" in cellulose (Luo and Wang, 2017). The absorbance bands around 894, 1020, 1155 , and $1369 \mathrm{~cm}^{-1}$ were associated with the $\mathrm{C}-\mathrm{H}$ rocking vibrations, $\mathrm{C}-\mathrm{O}$ stretching, $\mathrm{C}-\mathrm{O}-\mathrm{C}$ asymmetric valence vibration and $\mathrm{C}-\mathrm{H}_{2}$ rocking vibration, respectively, where these peaks are ascribed to cellulose form of the carbohydrates. These different bands can be seen in all spectra, regardless of the purification of the cellulose fibres (Salaberria et al., 2015).

\subsubsection{Thickness and mechanical properties of MCF/ TPS composite films}

The MCF/TPS composite films were prepared via the casting method using a different amount of MCF as a reinforcement agent $(0,1,5$, and $10 \mathrm{wt} \%$ of TPS). The films obtained were flexible, transparent, smooth and easy to be peeled off. There was no significant difference in appearance between the neat starch film and the MCF/ TPS composite films. Table 1 shows the thickness and tensile properties of the MCF/TPS composite films.

Table 1. Thickness and tensile properties of TPS and MCF/ TPS composite films.

\begin{tabular}{lccc}
\hline $\begin{array}{c}\text { Types of } \\
\text { sample }\end{array}$ & $\begin{array}{c}\text { Thickness of } \\
\text { films }(\mathrm{mm})\end{array}$ & $\begin{array}{c}\text { Tensile } \\
\text { strength }(\mathrm{MPa})\end{array}$ & $\begin{array}{c}\text { Elongation at } \\
\text { break }(\%)\end{array}$ \\
\hline $\begin{array}{l}\text { TPS } \\
1 \mathrm{wt} \%\end{array}$ & $0.078 \pm 0.07^{\mathrm{a}}$ & $7.49 \pm 1.87^{\mathrm{a}}$ & $9.18 \pm 0.81^{\mathrm{a}}$ \\
$\mathrm{MCF} / \mathrm{TPS}$ & $0.089 \pm 0.02^{\mathrm{b}}$ & $12.51 \pm 0.81^{\mathrm{b}}$ & $10.87 \pm 1.61^{\mathrm{a}}$ \\
$5 \mathrm{wt} \%$ & & $8.90 \pm 0.33^{\mathrm{a}}$ & $2.47 \pm 0.23^{\mathrm{b}}$ \\
$\mathrm{MCF} / \mathrm{TPS}$ & $0.094 \pm 0.02^{\mathrm{b}}$ & & \\
$10 \mathrm{wt} \%$ & & $8.67 \pm 1.82^{\mathrm{a}}$ & $5.74 \pm 3.00^{\mathrm{b}}$ \\
$\mathrm{MCF} / \mathrm{TPS}$ & $0.101 \pm 0.02^{\mathrm{c}}$ & & \\
\hline
\end{tabular}

Means in the same column, with the same lower-case letters, are not significantly different $(\mathrm{p}>0.05)$.

From Table 1, it can be seen that there is a linear increment in the thickness of the composite films with the increase in the concentration of MCF added to the films. The thickness of the composite films increased mainly due to the presence of the MCF in the starch matrix. Furthermore, since the size of the MFC was relatively large, the increment of the film thickness was clearer. The data reported here confirm the association of thickness with the solid content of the films, as reported by Reddy and Rhim (2014).

As can be inferred from Table 1, the mechanical properties of TPS were greatly influenced by the concentration of the MCF. It is obvious that $1 \mathrm{wt} \%$ of MCF addition was able to improve the tensile strength 


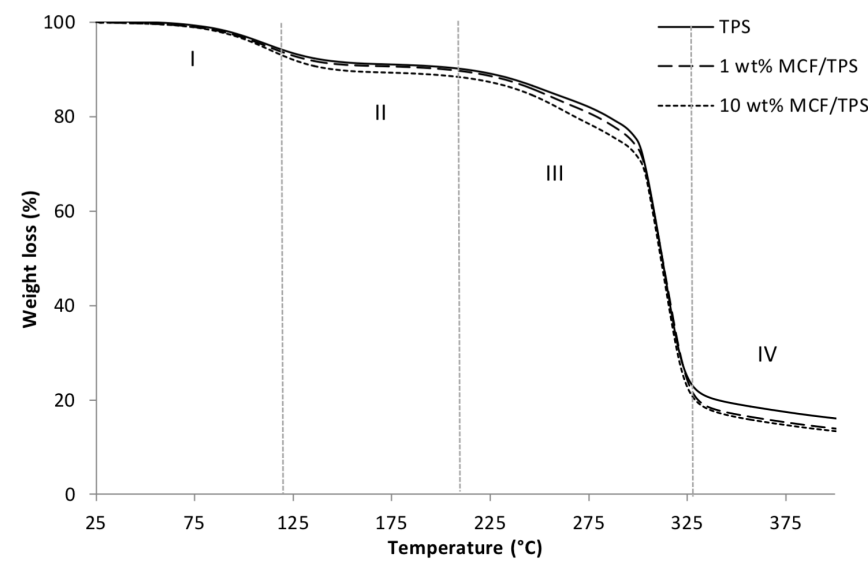

Figure 3a. TGA curves for non-reinforced TPS, $1 \mathrm{wt} \% \mathrm{MCF} /$ TPS, and $10 \mathrm{wt} \% \mathrm{MCF} / \mathrm{TPS}$ composite films

(TS) of the films by $67 \%$, from $7.49 \mathrm{MPa}$ to $12.51 \mathrm{MPa}$. The elongation at break (EAB) values also shows an increment from $9.18 \%$ to $10.87 \%$ with the addition of 1 $\mathrm{wt} \%$ of MCF. This finding was probably due to good dispersion in the film matrix and the micron size of cellulose has allowed an effective contact area with the starch matrix. Furthermore, the chemical similarities between starch and cellulose may induce a strong intermolecular interaction between the molecules through hydrogen bonding. This, in turn, was able to intensify the adhesion of the MCF to the film matrix Chen et al. (2017) thus increased the TS. Not only that, the effective network between the MFC and the starch improves the flexibility of the composite films which is shown by the increment in EAB by $18.4 \%$. On the contrary, the addition of $5 \mathrm{wt} \%$ and $10 \mathrm{wt} \%$ of MCF caused a great reduction in the TS and the $\mathrm{EAB}$ values. The TS values obtained for $5 \mathrm{wt} \%$ and $10 \mathrm{wt} \% \mathrm{MCF} /$ TPS films were $8.90 \mathrm{MPa}$ and $8.67 \mathrm{MPa}$, respectively while the EAB values were $2.47 \%$ and $5.74 \%$, respectively. The reduction in TS and $\mathrm{EAB}$ values can be explained by the fact that an excess amount of MCF formed agglomerations and non-uniform stress distribution of the MCF within the film matrix. The MCF did not form an effective network with the film matrix and thus did not act as a reinforcing agent. Savadekar and Mhaske (2012) also mentioned that an excess amount of reinforcing agent could also cause phase separation, poor particle distribution and large agglomerates, which lead to poor mechanical properties. Nevertheless, the TS values obtained were still higher than the values obtained for the neat TPS due to the good dispersion and strong interaction between the MCF and TPS matrix

Interestingly, the tensile strength of the $1 \mathrm{wt} \% \mathrm{MCF} /$ TPS composite films in this study was much higher than those of $\mathrm{MCC} / \mathrm{starch}$ and $\mathrm{MFC} /$ starch composites reported in some literature. For instance, the tensile

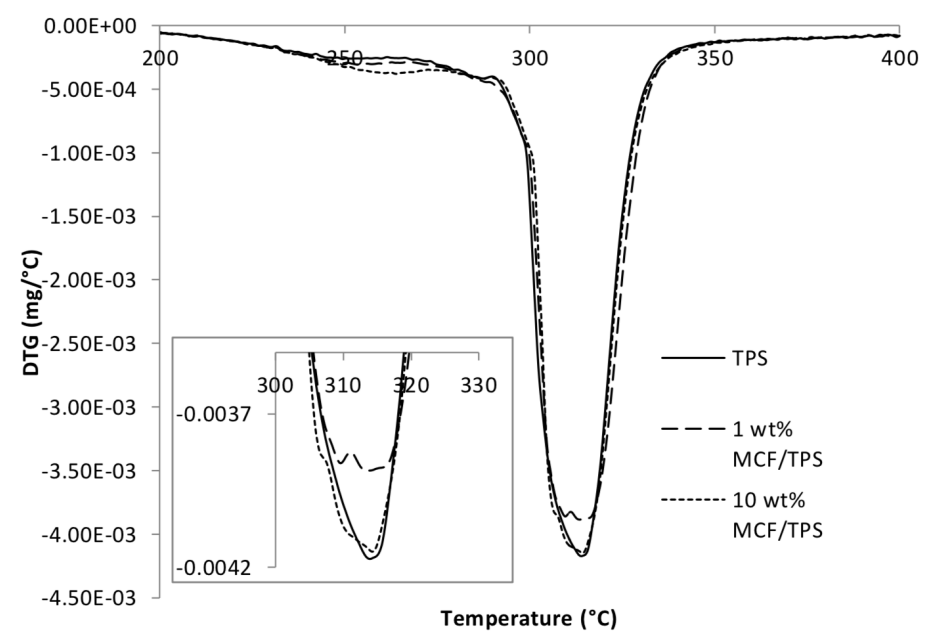

Figure $3 \mathrm{~b}$. DTG of non-reinforced TPS, $1 \mathrm{wt} \% \mathrm{MCF} / \mathrm{TPS}$, and $10 \mathrm{wt} \% \mathrm{MCF} / \mathrm{TPS}$ composite films

strength for the $\mathrm{MCC} / \mathrm{starch} /$ polyester blown films was $6.5 \mathrm{MPa}$ with $4 \%$ of MCC (Reis et al., 2017), while 3.9 $\mathrm{MPa}$ for MCC/modified potato starch (Wilpiszewska and Czech, 2014). Also, Chen et al. (2017) found that the tensile strength for MFC/hydroxypropyl starch was in the range of $6.25 \mathrm{MPa}$ to $12.54 \mathrm{MPa}$ with the addition of $3 \mathrm{wt} \%, 6 \mathrm{wt} \%$, and $9 \mathrm{wt} \%$ of MFC. In general, these results confirm the fact that micron-sized cellulose fibres produced in this work could be a reinforcing agent for bio-composite films but only to a certain limit. Meanwhile, the EAB values decreased for the $5 \mathrm{wt} \%$ and $10 \mathrm{wt} \%$ of MCF loadings which can be ascribed to the stiffness characteristics of native cellulose.

\subsection{Thermal gravimetric analysis (TGA)}

Table 2. Degradation temperature on maximum weight loss rate and char residue $(\%)$

\begin{tabular}{lccc}
\hline Types of sample & $\begin{array}{c}\text { Degradation } \\
\text { temperature } \\
\text { (max DTG } \\
\text { peak) }\left({ }^{\circ} \mathrm{C}\right)\end{array}$ & $\begin{array}{c}\text { Weight } \\
\text { loss at } \\
\text { max DTG } \\
\text { peak }(\%)\end{array}$ & $\begin{array}{c}\text { Char } \\
\text { residue } \\
(\%)\end{array}$ \\
\hline TPS & 313 & 51.3 & 12 \\
$1 \mathrm{wt} \% \mathrm{MCF} / \mathrm{TPS}$ & 309 & 53.5 & 10.1 \\
$10 \mathrm{wt} \% \mathrm{MCF} / \mathrm{TPS}$ & 312 & 55.0 & 9.3 \\
\hline
\end{tabular}

The thermogravimetric curves and the derivative thermogravimetry (DTG) curves of the neat TPS and the $1 \mathrm{wt} \%$ and $10 \mathrm{wt} \%$ of MCF/TPS composite are illustrated in Figure 3a and Figure 3b, respectively, and the relevant data are shown in Table 2. From Figure 3a, it can be seen that the neat TPS and the MCF/TPS composites films are showing similar degradation behaviour from $25^{\circ} \mathrm{C}$ to $500^{\circ} \mathrm{C}$. Generally, the TGA curves can be divided into several phases. The initial phase occurred from $65^{\circ} \mathrm{C}$ to $110^{\circ} \mathrm{C}$ indicating evaporation of moisture from the films. There is no obvious difference could be seen among the samples due to similar contents of water as well as glycerol. Figure 3a. TGA curves for non-reinforced TPS, $1 \mathrm{wt} \% \mathrm{MCF} /$ TPS, and $10 \mathrm{wt} \%$ MCF/TPS composite films. 
The second degradation step can be observed around $120^{\circ} \mathrm{C}$ to $200^{\circ} \mathrm{C}$ due to the evaporation of glycerol (Sanyang et al., 2015) together with the plasticizer compounds that were indirectly carried by water molecules (Ilyas et al., 2018). This trend supports the fact that the mass loss before the onset temperature is attributed to the volatilization of both water and glycerol (Ma et al., 2008). The third degradation steps were observed around $210^{\circ} \mathrm{C}$ to $285^{\circ} \mathrm{C}$, respectively attributed to the complex process of starch degradation. This is in agreement with the report by Mathew and Dufresne (2002) and Sanyang et al. (2015), whereby the weight loss after the evaporation of water and plasticizer was ascribed to the dehydration of the saccharide rings and depolymerisation. The temperature range was lower than those reported in previous work, which was around $250^{\circ}$ C-300 ${ }^{\circ} \mathrm{C}$ (Piyada et al., 2013). A possible explanation for this might be due to the difference in the amyloseamylopectin content of the starch used to prepare the films. The starch used in this study could have higher amylopectin than amylose that caused extensive branching (Rindlav-Westling et al., 1998), and therefore weakens the intramolecular bonding between the starch molecules. This, in turn, leads to the mentioned complex processes occurred at a lower temperature range.

Figure $3 \mathrm{a}$ also shows the maximum decomposition rate occurred at around $309^{\circ} \mathrm{C}$ to $318^{\circ} \mathrm{C}$, which is very similar for all films, reflected by the drastic weight loss. This is followed by the char residue formation in the temperature range of $325^{\circ} \mathrm{C}-500^{\circ} \mathrm{C}$. The most striking observation was that the weight loss for both of the MCF/TPS composite films is higher than the neat TPS. This finding shows that the MCF did not improve the thermal resistance of starch films. Furthermore, the DTG curves in Figure $3 \mathrm{~b}$ depicts that there is no significant difference in the maximum degradation peaks between the films. The temperature at maximum weight loss and the char yield residue (\%) for all films were listed in Table 2. From Table 2, it can be seen that the char residue for the neat TPS is higher than the MCF/TPS composite films. This might be related to the presence of hemicellulose components within and between the cellulose fibres. The presence of hemicelluloses components might reduce the crystallinity of the MCF and cause the composite films to degrade faster and easier and hence, the weight loss obtained was much higher than the neat TPS film. This idea is supported by Ilyas et al. (2018) who speculated that the strong association between the hemicelluloses and cellulose fibrils would decrease the crystallinity of the cellulose fibrils thus accelerated the onset of the thermal degradation process.

\section{Conclusion}

Microcellulose fibres (MCF) was successfully prepared via the treatment of $\mathrm{NaOH} / \mathrm{urea}$, combined with ultrasonication. This facile, safe, and low-cost preparation method may be an interesting research to be explored further. The FESEM revealed that the size of the MCF was in the range of 2 to $15 \mu \mathrm{m}$ in diameter and $150 \mu \mathrm{m}$ to hundreds of micrometers in length. The incorporation of $1 \mathrm{wt} \% \mathrm{MCF}$ improved the TS and $\mathrm{EAB}$ values, approximately $67 \%$ and $18.4 \%$ increment, respectively. The improvement is due to the good adhesion and strong intermolecular interaction between the TPS matrix and the cellulose fibres. At $5 \mathrm{wt} \%$ and 10 wt $\%$ loadings of MCF, the composite films showed a decrease in TS and $\mathrm{EAB}$, due to MCF agglomerations within the film matrix. On the other hand, the MCF did not show any significant thermal resistance, suggesting the presence of hemicellulose compounds that reduce the crystallinity of cellulose fibrils, leading to lower degradation temperature as compared to neat TPS films. Taken together, this work may offer significant insights for future research especially for the synthesis of microcellulose fibres and their potential use as reinforcement in bio-based polymers for food packaging applications.

\section{Acknowledgement}

This work was financially supported by the Fundamental Research Grant Scheme (FRGS), Ministry of Higher Education, Malaysia (Project no. 03-01-161873FR, Vote no. 5524980).

\section{References}

Abdul-Khalil, H.P.S., Tye, Y.Y., Saurabh, C.K., Leh, C.P., Lai, T.K., Chong, E.W.N. and Syakir, M.I. (2017). Biodegradable polymer films from seaweed polysaccharides: A review on cellulose as a reinforcement material. Express Polymer Letters, 11 (4), 244-265. https://doi.org/10.3144/ expresspolymlett.2017.26

Alcàzar-Alay, S.C. and Meireles, M.A.A. (2015). Physicochemical properties. Modifications and applications of starches from different botanical sources. Food Science and Technology (Campinas), 35(2), 215-236. https://doi.org/10.1590/1678457X.6749

Ali, M.E., Yong, C.K., Ching, Y.C., Chuah, C.H. and Liou, N.S. (2014). Effect of single and double stage chemically treated kenaf fibres on mechanical properties of polyvinyl alcohol film. Bioresources, 10(1), 822-838. https://doi.org/10.15376/ biores.10.1.822-838 
ASTM. (2002). Standard Test Method Tensile Properties of Thin Plastic Sheeting (D882-02). Pennsylvania: ASTM International

Avérous, L. and Halley, P.J. (2009). Biocomposites based on plasticized starch. Biofuels, Bioproducts, and Biorefining, 3(3), 329-343. https:// doi.org/10.1002/bbb.135

Azrina, Z.A.Z., Beg, M.D.H., Rosli, M.Y., Ramli, R., Junadi, N. and Alam, A.K.M.M. (2017). Spherical nanocrystalline cellulose (NCC) from oil palm empty fruit bunch pulp via ultrasound assisted hydrolysis. Carbohydrate Polymers, 162, 115-120. https://doi.org/10.1016/j.carbpol.2017.01.035

Chen, J., Long, Z., Wang, J., Wu, M., Wang, F., Wang, B. and Lv, W. (2017). Preparation and properties of microcrystalline cellulose/hydroxypropyl starch composite films. Cellulose, 24(10), 4449-4459. https://doi.org/10.1007/s10570-017-1423-6

Coelho, C.C.S., Cerquiera, M.A., Pereira, R.N., Pastrana, L.M., Freuras-Silva, O., Vicente, A.A. and Teixeira, J.A. (2017). Effect of moderate electric fields in the properties of starch and chitosan films reinforced with microcrystalline cellulose. Carbohydrate Polymers, 174, 1181-1191. https://doi.org/10.1016/ j.carbpol.2017.07.007

European Bioplastics (2017). Report European Bioplastics. Bioplastics Market Data 2017. Retrieved from website: http://docs.european-bioplastics.org/

El-Hadi, A.M. (2013). Influence of microcrystalline cellulose fiber (MCCF) on the morphology of poly (3-hydroxybutyrate) (PHB). Colloid and Polymer Science, 291(3), 743-756. https://doi.org/10.1007/ s00396-012-2784-x

Geyer, R., Jambeck, J.R. and Law, K.L. (2017). Production, use, and fate of all plastics ever made. Science Advances, 3, e1700782. https:// doi.org/10.1126/sciadv.1700782

Haafiz, M.M., Hassan, A., Zakaria, Z., Inuwa, I.M., Islam, M.S. and Jawaid, M. (2013). Properties of polylactic acid composites reinforced with oil palm biomass microcrystalline cellulose. Carbohydrate Polymers, 98(1), 139-145. https://doi.org/10.1016/ j.carbpol.2013.05.069

Ilyas, R.A., Sapuan, S.M. and Ishak, M.R. (2018). Isolation and characterization of nanocrystalline cellulose from sugar palm fibers (Arenga Pinnata). Carbohydrate Polymers, 181, 1038-1051. https:// doi.org/10.1016/j.carbpol.2017.11.045

Jiang, Z., Fang, Y., Xiang, J., Lu, A., Kang, H., Huang, Y. and Zhang, L. (2014). Intermolecular interactions and $3 \mathrm{D}$ structure in cellulose- $\mathrm{NaOH}$-urea aqueous system. The Journal of Physical Chemistry B, 118,
10250-10257. https://doi.org/10.1021/jp501408e

Jonoobi, M., Khazaeian, A., Tahir, P.M., Asry, S.S. and Oksman, K. (2011). Characteristics of cellulose nanofibers isolated from rubberwood and empty fruit bunches of oil palm using chemo-mechanical process. Cellulose, 18(4), 1085-1095. https:// doi.org/10.1007/s10570-011-9546-7

Jonoobi, M., Oladi, R., Davoudpour, Y., Oksman, K., Dufrense, A., Hamzeh. and Davoodi, R. (2015). Different preparation methods and properties of nanostructured cellulose from various natural resources and residues: A review. Cellulose, 22(2), 935-969. https://doi.org/10.1007/s10570-015-0551-0

Lani, N., Nagadi, N., Johari, A. and Jusoh, M. (2014). Isolation, characterization, and application of nanocellulose from oil palm empty fruit bunch fiber as nanocomposites. Journal of Nanomaterials (702538), 1-9. https://doi.org/10.1155/2014/702538

Lendvai, L., Karger-Kocsis, J., Kmetty, Á. and Drakopoulus, S.X. (2016). Production and characterization of microfibrillated cellulosereinforced thermoplastic starch composites. Journal of Applied Polymer Science, 133(2), 42397. https:// doi.org/10.1002/app.42397

Li, C.G., Wang, X.P., Liu, L., Chui, J.H. and Zhang, R. (2012). The effect of corn stalk microcrystalline cellulose on thermal and mechanical properties of chitosan composites. Applied Mechanics and Materials, 174-177, 1038-1041. https:// doi.org/10.4028/www.scientific.net/AMM.174177.1038

Li, C., Luo, J., Qin, Z., Chen, H., Gao, Q. and Li, J. (2015). Mechanical and thermal properties of microcrystalline cellulose-reinforced soy-protein isolate-gelatin eco-friendly films. RSC Advances, 5 (70), 56518-56525. https://doi.org/10.1039/ C5RA04365D

Liu, W., Fei, M.E., Ban, Y., Jia, A. and Qiu, R. (2017). Preparation and evaluation of green composites from microcrystalline cellulose and a soybean-oil derivative. Polymers, 9(541), 1-13. https:// doi.org/10.3390/polym9100541

Luo, X. and Wang, X. (2017). Preparation and characterization of nanocellulose fibers from $\mathrm{NaOH} /$ urea pre-treatment of oil palm fibers. Bioresources, 12(3), 5826-5837. https://doi.org/10.15376/ biores.12.3.5826-5837

Ma, X., Chang, P.R. and Yu, J. (2008). Properties of biodegradable thermoplastic pea starch/ carboxymethyl cellulose and pea starch/ microcrystalline cellulose composites. Carbohydrate Polymers, 72(3), 369-375. https://doi.org/10.1016/ 
j.carbpol.2007.09.002

Mali, S., Sakanaka, L.S., Yamashita, F. and Grossmann, M.V.E. (2005). Water sorption and mechanical properties of cassava starch films and their relation to plasticizing effect. Carbohydrate Polymers, 60(3), 283-289.

https://doi.org/10.1016/

j.carbpol.2005.01.003

Mandal, A. and Chakrabarty, D. (2011). Isolation of nanocellulose from waste sugarcane bagasse (SCB) and its characterization. Carbohydrate Polymers, 86 (3), 1291-1299. https://doi.org/10.1016/ j.carbpol.2011.06.030

Mathew, A.P. and Dufrense, A. (2002). Morphological investigation of nanocomposites from sorbitol plasticized starch and tunicin whiskers. Biomacromolecules, 3(3), 609-617. https:// doi.org/10.1021/bm0101769

Maulida, Siagian, M. and Tarigan, P. (2016). Production of starch based bioplastic from cassava peel reinforced with microcrystalline cellulose Avicel PH101 using sorbitol as plasticizer. Journal of Physics: Conference Series, 710, 012012.

Mohamed, R., Mohd, M., Nurazzi, N., Siti Aisyah, M.I. and Mohd Fauzi, F. (2017). Swelling and tensile properties of starch glycerol system with various crosslinking agents. IOP Conference Series: Materials Science and Engineering, 223, 012059.

Moràn, J.I., Alvarez, V.A., Cyras, V.P. and Vàzquez, A. (2008). Extraction of cellulose and preparation of nanocellulose from sisal fibers. Cellulose, 15(1), 149 -159. https://doi.org/10.1007/s10570-007-9145-9

Othman, S.H. (2014). Bio-nanocomposite materials for food packaging applications: Types of biopolymer and nano-sized filler. Agriculture and Agricultural Science Procedia, 2, 296-303. https:// doi.org/10.1016/j.aaspro.2014.11.042

Pelissari, F.M., Grossmann, M.V.E., Yamashita, F. and Pineda, E.A.G. (2009). Antimicrobial, mechanical, and barrier properties of cassava starch-chitosan films incorporated with oregano essential oil. Journal of Agricultural and Food Chemistry, 57(16), 7499-7504. https://doi.org/10.1021/jf9002363

Piyada, K., Waranyou, S. and Thawien, W. (2013). Mechanical, thermal, and structural properties of rice starch films reinforced with rice starch nanocrystals. International Food Research Journal, 20(1), 439449.

Qi, X., Jing, M., Liu, Z., Dong, P., Liu, T. and Fu, Q. (2016). Microfibrillated cellulose reinforced biobased poly (propylene carbonate) with dual responsive shape memory properties. RSC Advances, 6, 7560-7567. https://doi.org/10.1039/C5RA22215J
Reddy, J.P. and Rhim, J.W. (2014). Characterization of bionanocomposite films prepared with agar and paper-mulberry pulp nanocellulose. Carbohydrate Polymers, 110, 480-488. https://doi.org/10.1016/ j.carbpol.2014.04.056

Reis, M.O., Olivato, J.B., Zanela, J., Yamashita, F. and Grossmann, M.V.E. (2017). Influence of microcrystalline cellulose in thermoplastic starch/ polyester blown films. Polímeros 27(2), 129-135. https://doi.org/10.1590/0104-1428.2338

Rindlav-Westling, A., Stading, M., Hermansson A.M. and Gatenholm, P. (1998). Structure, mechanical and barrier properties of amylose and amylopectin films. Carbohydrate Polymers, 36(2-3), 217-224. https:// doi.org/10.1016/S0144-8617(98)00025-3

Sadegh-Hassani, F. and Nafchi, M.A. (2014). Preparation and characterization of bionanocomposite films based on potato starch/ halloysite nanoclay. Internatonal Journal of Biological Macromolecules, 67, 458-462. https:// doi.org/10.1016/j.ijbiomac.2014.04.009

Salaberria, A.M., Diaz, R.H., Labidi, J. and Fernandes, S.C.M. (2015). Role of chitin nanocrystals and nanofibers on physical, mechanical and functional properties in thermoplastic starch films. Food Hydrocolloids, 46, 93-102. https://doi.org/10.1016/ j.foodhyd.2014.12.016

Sanyang, M.L., Sapuan, S.M., Jawaid, M., Ishak, M.R. and Sahari, J. (2015). Effect of plasticizer type and concentration on tensile, thermal, and barrier properties of biodegradable films based on sugar palm (Arenga pinnata) starch. Polymers, 7(6), 1106 -1124. https://doi.org/10.3390/polym7061106

Savadekar, N.R. and Mhaske, S.T. (2012). Synthesis of nanocellulose fibers and effect on thermoplastic starch films. Carbohydrate Polymers, 89(1), 146151. https://doi.org/10.1016/j.carbpol.2012.02.063

Shankar, S., Reddy, J.P., Rhim, J.W. and Kim, H.Y. (2015). Preparation, characterization, and antimicrobial activity of chitin nanofibrils reinforced carrageenan nanocomposite films. Carbohydrate Polymers, 117, 468-475. https://doi.org/10.1016/ j.carbpol.2014.10.010

Shankar, S. and Rhim, J.-W. (2016). Preparation of nanocellulose from micro-crystalline cellulose: The effect on the performance and properties of agarbased composite films. Carbohydrate Polymers, 135, 18-26. https://doi.org/10.1016/j.carbpol.2015.08.082

Siquera, G., Bras, J. and Dufrense, A. (2010). Cellulosic bionanocomposites: A review of preparation, properties and applications. Polymers, 2(4), 728-765. https://doi.org/10.3390/polym2040728 
Soykeabkaew, N., Tawichai, N., Thanomsilp, C. and Suwantong, O. (2017). Nanocellulose-reinforced "green" composite materials. Walailak Journal of Science and Technology, 14(5), 353-368.

Trache, D., Hussin, M.H., Hui Chuin, C.T., Sabar, S., Fazita, M.R.N., Taiwo, O.F.A. and Haafiz, M.K.M. (2016). Microcrystalline cellulose: Isolation, characterization, and bio-composites application: A review. International Journal of Biological Macromolecules, 93(Part A), 789-804. https:// doi.org/10.1016/j.ijbiomac.2016.09.056

Wang, S., Sun, P., Liu, M., Lu, A. and Zhang, L. (2017). Weak interactions and their impact on cellulose dissolution in an alkali/urea aqueous system. Physical Chemistry Chemical Physics, 19(27), 17909 -17917. https://doi.org/10.1039/C7CP02514A

Wilpiszewska, K. and Czech, Z. (2014). Citric acid modified potato starch films containing microcrystalline cellulose reinforcement - properties and application. Starch-Stärke, 66(7-8), 660-667. https://doi.org/10.1002/star.201300093

Wittaya, T. (2012). Rice Starch-Based Biodegradable Films: Properties Enhancement. In Ayman Amer Eissa (Ed). Structure and Function of Food Engineering. IntechOpen, Retrieved from website: https://www.intechopen.com/books/structure-andfunction-of-food-engineering/rice-starch-basedbiodegradable-films-properties-enhancement.

Zhang, S. Wang, W., Li, F. and Yu, J. (2013). Swelling and dissolution of cellulose in $\mathrm{NaOH}$ aqueous solvent systems. Cellulose Technology and Chemistry, 67(9-10), 671-679.

Zhou, J. Zhang, L. and Cai, J. (2004). Behaviour of cellulose in $\mathrm{NaOH} / \mathrm{urea}$ aqueous solution characterized by light scattering and viscometry. Journal of Polymer Science, Part B: Polymer Physics, 42(2), 347-353. https://doi.org/10.1002/ polb.10636 